\title{
A COLABORAÇÃO PREMIADA COMO INSTRUMENTO DE INDIVIDUALIZAÇÃO DE CONDUTAS NOS CRIMES EMPRESARIAIS: ESTUDO DE CASO
}

\author{
Guilherme de Oliveira Alonso \\ Mateus Eduardo Siqueira Nunes Bertoncini
}

\section{RESUMO}

Pretende o artigo analisar um problema corriqueiro das imputações e condenações relacionadas a crimes empresariais - a dificuldade de individualização de condutas - e a possível utilização de um meio pouco pensado como instrumento de garantia - a colaboração premiada - como solução. Para tanto, analisar-se-á uma sentença em que depoimentos de colaboradores fizeram parte do arcabouço probatório da condenação de empresários de empreiteira pela prática de crimes cometidos durante a atividade empresarial. O objetivo é verificar se, nesse caso específico, as palavras dos réus colaboradores contribuíram para a delimitação real da autoria delitiva dos acusados e afastaram eventuais presunções de responsabilidade penal.

Palavras-chave: Direito Penal; Processo Penal; individualização de condutas; colaboração premiada; crimes empresariais.

\section{THE JUDICIAL COLLABORATION AS AN INSTRUMENT OF INDIVIDALIZATION OF CONDUCTS OF CORPORATE CRIMES: CASE STUDY}

\begin{abstract}
The goal of this essay is to analyze a problem of imputations and criminal convictions related to corporate crimes - the difficulty of individualizing conducts - and the possible use of a medium that is not thought of as a guarantee instrument - the judicial collaboration - as a solution. To do so, it will analyze a criminal conviction in which collaborators' testimonies were part of the probative framework. The aim is to verify whether, in this specific case, the words of the collaborating defendants contributed to the delimitation of the authorship of the accused and removed any presumptions of responsibility.
\end{abstract}

Keywords: Criminal Law; Criminal proceedings; individualization of conducts; judicial collaboration; corporate crimes. 


\section{INTRODUÇÃO}

O presente artigo pretende analisar se o instituto processual penal da colaboração premiada pode, além de funcionar como instrumento punitivo de grande eficiência para a apuração de crimes praticados por meio de organizações criminosas, resolver um problema recorrente nos crimes de natureza empresarial: a dificuldade de individualização de condutas.

Essa questão é, sem dúvida, significante na esfera do direito punitivo: qual seria a relação entre as garantias do processo penal e um instituto de valor probatório questionável que visa, antes de tudo, desmantelar esquemas criminosos de magnitude por meio da palavra de coautores e partícipes dos crimes (muitos dos quais não mereceriam, em outra situação, qualquer credibilidade por seus depoimentos)?

Conforme se pretende estudar adiante, pode haver uma relação relevante, questionando-se em que medida esse instituto, tão famoso em razão dos inúmeros processos da Operação Lava-Jato (além de outras grandes investigações criminais e ações penais que se espalharam pelo país), pode ter um caráter de instrumento de garantia no processo penal. Com efeito, pretende-se verificar se, na sua utilização prática, a colaboração premiada pode resolver os problemas relacionados à denúncia genérica (ou à denúncia não exaustiva na descrição das condutas praticadas por executivos e administradores de empresas nas quais foram praticados crimes) e às eventuais condenações criminais presuntivas (isto é, presumindo-se a autoria do dirigente somente em razão de sua posição na hierarquia da empresa).

A estrutura deste estudo terá como fundação a indicação do problema da individualização de condutas e a posição da doutrina e da jurisprudência sobre o tema. Após um breve estudo sobre o instituto da colaboração premiada, analisar-se-á caso concreto, extraído da Operação Lava-Jato, para verificar se, na sentença correspondente, as provas decorrentes da colaboração foram utilizadas para a formalização da autoria delitiva.

Em outros termos, empregar-se-ão os métodos teórico-bibliográfico e de estudo de caso para o enfrentamento da questão central da pesquisa.

Por derradeiro, há que se registrar que a resposta fruto desse trabalho está a exigir novos estudos e a análise de outras amostras, para que se tenha uma resultante de maior densidade e certeza, não alcançável no breve espaço deste ensaio. 


\section{O PROBLEMA DA INDIVIDUALIZAÇÃO DE CONDUTAS NOS CRIMES EMPRESARIAIS}

O Código de Processo Penal estabelece as diretrizes para a responsabilização penal de qualquer indivíduo suspeito de ter cometido um crime. Desde o conhecimento do fato até a prolação de sentença condenatória, há a indicação dos requisitos legais para o reconhecimento de que alguém incorreu em uma conduta prevista no Código Penal ou na legislação especial.

Por exemplo, o art. $4^{\circ}$, que trata da atividade policial civil, estabelece que " $a$ polícia judiciária será exercida pelas autoridades policiais no território de suas respectivas circunscrições e terá por fim a apuração das infrações penais e da sua autoria”. $\mathrm{O}$ art. 27, que prevê o acesso popular ao Ministério Público para a notícia de infração penal, dispõe que “qualquer pessoa do povo poderá provocar a iniciativa do Ministério Público, nos casos em que caiba a ação pública, fornecendo-lhe, por escrito, informações sobre ofato e a autoria e indicando o tempo, o lugar e os elementos de convicção". O mesmo ocorre em relação ao dispositivo que trata da representação do ofendido (ou de seu representante legal ou procurador), que, no $\S 2^{\circ}$ do art. 39 , afirma que "a representação conterá todas as informações que possam servir à apuração do fato e da autoria".

Quanto à ação penal, o art. 41, que trata dos requisitos da inicial acusatória, estabelece que "a denúncia ou queixa conterá a exposição do fato criminoso, com todas as suas circunstâncias, a qualificação do acusado ou esclarecimentos pelos quais se possa identificálo, a classificação do crime e, quando necessário, o rol de testemunhas". Por sua vez, o art. 386, IV e V, prescrevem que o "o juiz absolverá o réu” quando estiver "provado que o réu não concorreu para a infração penal" ou quando "não existir prova de ter o réu concorrido para a infração penal".

A leitura do Código de Processo Penal parece deixar muito claro que o processo penal brasileiro se orienta, quando se trata de responsabilização criminal, pela indispensabilidade de indicação e comprovação da autoria delitiva - para, justamente, a responsabilização penal subjetiva, devidamente individualizada.

Os portadores dessa conclusão, porém, esquecem-se que o CPP foi criado por meio do Decreto-Lei n ${ }^{\circ} 3.689$, de 3 de outubro de 1941, contando atualmente com mais de 75 (setenta e cinco) anos. Desde então, mudanças extremamente significativas ocorreram no processo de criminalização de condutas, surgindo uma "inflação legislativa", na expressão de René Ariel 
Dotti $^{1}$, com a absorção, pelo Direito Penal, de práticas pouco afeitas ao regime de individualização de autoria do Código de Processo Penal.

Dotti, aliás, ao afirmar que "são inúmeras as leis que a todo momento estão sendo impostas desordenamente do mercado jurídico que trata dos delitos e das penas" ${ }^{\prime 2}$, ratifica o que já vinha sendo dito por Nelson Hungria nos anos 50:

\begin{abstract}
Mas o prurido legisferante no Brasil é coceira de urticária. Muda-se de lei como se muda de camisas. Reformam-se periodicamente as leis sem quê nem para quê, ou pelo só capricho de as reformar. E quase sempre para pior. Quando se anuncia a reforma de uma lei em torno de algum instituto jurídico ou fato social, tem-se a impressão de que vai ser corrigida uma falha sensível ou introduzido um critério de solução mais conforme com o estilo da vida contemporânea. Pura ilusão. E ainda bem quando tudo se limita a uma simples mão de cal nas paredes e a mudar-se o número da casa. As mais das vezes, porém, o que vem a ocorrer é o meticuloso desarranjo daquilo que estava arrumado, ou uma inadequação maior do que a anterior. $^{3}$
\end{abstract}

Alexandre Knopfholz lista uma série de leis que foram criadas nas últimas décadas que, de fato, acabam por corromper os paradigmas de responsabilização penal na forma como exige o Código Penal ${ }^{4}$. Como exemplo, podem-se citar as Leis $\mathrm{n}^{\mathrm{o}} 7.492 / 86$ (crimes contra o Sistema Financeiro Nacional), 8.137/90 (crimes contra a ordem tributária), 8.176/90 (crimes contra a ordem econômica), 8.666/93 (crimes de licitação) e 9.605/98 (crimes ambientais). O autor ressalta que "se somados, são dezenas de tipos penais, dirigidos basicamente aos empresários e agentes financeiros" $"$. E segue:

Com efeito, criminalizaram-se condutas até então relegadas a outras esferas do Direito ou da Administração Pública. A não anotação dolosa em Carteira de Trabalho e Previdência Social, por exemplo, é, hoje, crime punido com reclusão de 2 a 6 anos (CP, art. 297, § $3^{\circ}$, II e $\left.\S 4^{\circ}\right)$. A simples manutenção de divisas no exterior sem a declaração à autoridade competente é, igualmente, um delito autônomo, de igual apenamento (Lei 7.492/86, art. 22, parágrafo único). ${ }^{6}$

Knopfholz também alerta, para os efeitos deste estudo, que os crimes empresariais tornaram-se objetivo ideológico dos órgãos de persecução penal. Ou seja, além de se tratar de um ramo do Direito novo e assistemático (e, de certa forma, pouco compatível com a ordem processual), trata-se de área de grande foco de atuação do Estado e do Direito Penal. ${ }^{7}$

Se, por um lado, a mudança é certamente bem vinda em um país em que a corrupção é generalizada e no qual se tem notícia de inúmeros casos de crimes envolvendo a atividade 
empresarial em conluio com agentes públicos criminosos, por outro, há um problema de natureza jurídica.

Como se afirmou acima, o processo penal brasileiro tem como objetivo primário a comprovação do binômio materialidade/autoria delitivas, não devendo haver - em tese responsabilização criminal quando ambos os elementos não sejam cumulativamente verificados, por provas produzidas à luz do contraditório, na sentença condenatória penal. $\mathrm{Ou}$ seja, é indispensável, para que se fale em responsabilidade penal, que tanto se tenha a prova do crime, quanto a prova de sua autoria.

Com os crimes cometidos no âmbito da empresa, essa prova é inequivocamente mais complexa de se obter. Knopfholz traz o panorama:

É indubitável que os crimes econômicos são, em sua esmagadora maioria, empresariais. Segundo pesquisa realizada na Alemanha pelo Instituto Max Planck instituição de ponta no campo da pesquisa científica e social - cerca de $80 \%$ (oitenta por cento) dos crimes econômicos ocorrem no âmbito de pessoas jurídicas. E, como é cediço, nestas ocorre um aparente 'sumiço' de responsabilidades, que se esvaem na sua complexa estrutura organizacional. Torna-se difícil identificar a autoria de um crime, diante da existência de um quadro orgânico hierarquizado nas atividades empresariais. A natureza orgânica, a descentralização na tomada de decisões e a divisão de funções entre os integrantes da sociedade dificultam (quando não impedem) uma fácil definição dos autores de tais modalidades delitivas. ${ }^{8}$

No mesmo sentido, Vicente Musacchio:

\begin{abstract}
En el ambito de la responsabilidad penal, se producen problemas importantes para la determinación de la responsabilidad individual cuando el delito es cometido en el contexto de una empresa por las siguientes características del comportamiento: delegación de funciones, división del trabajo, complejización de los nexos causales, pluralidade de sujeitos intervenientes, todo esto produce, en definitiva, una disosiación entre quienes actúan y quienes responden penalmente, pudiendo recaer el peso de la responsabilidad en la jerarquia de la organización (responsabilidad del titular de la empresa) o en la base de la misma (responsabilidad de los representantes). ${ }^{9}$
\end{abstract}

Evidentemente, o problema não afeta apenas o caráter terminativo do processo - a sentença condenatória. Há um problema prévio quanto à própria instauração da ação penal. Afinal, o art. 41 do CPP exige, como requisito para o recebimento da denúncia, a descrição do fato "com todas as suas circunstâncias", o que, evidentemente, envolve a descrição das condutas praticadas pelo autor do crime. 
A jurisprudência já pôde se manifestar quanto a essa parte do problema. Knopfholz teve o trabalho de verificar, em pesquisa publicada em 2013, qual o posicionamento dos Tribunais Superiores quanto à denúncia genérica nos crimes econômicos. A partir de mais de 200 (duzentos) precedentes dos 20 (vinte) anos anteriores à publicação, o autor constatou, quanto ao Superior Tribunal de Justiça, que "a jurisprudência do final do último século foi marcadamente favorável à denúncia genérica" ${ }^{10}$. Ou seja, exceto alguns julgados em sentido oposto, a maioria dos precedentes admitia o recebimento de denúncia que não descrevia as condutas praticadas pelo administrador da empresa por meio (ou no seio) da qual foram praticados os crimes econômicos. Como paradigma, Knopfholz citou o acórdão do Recurso em Habeas Corpus $n^{\circ}$ 906/MG, relatado pelo Ministro José Cândido, que afirmou o seguinte:

\begin{abstract}
Nos crimes societários é possível o acolhimento da denúncia, mesmo sem a definição da conduta de cada um dos participantes do delito. A instrução processual suprirá essa falha. (...) Se o inquérito não foi capaz de detalhar a participação dos réus, não é de recusar-se a inicial que não conseguiu ainda elementos para tal mister. Ora, se a denúncia pode ser, em qualquer tempo, aditada, tudo leva a crer que, oportunamente, a suposta falha pode ser suprida. ${ }^{11}$
\end{abstract}

Ao longo do tempo, adverte o autor, "passou-se, no início do novo século, a aceitá-la com a camuflagem de denúncia 'mais ou menos' genérica. E, a partir de meados dos anos 2000, a maioria das decisões exige a descrição da conduta de cada denunciado, ainda que de forma não pormenorizada." 12 São dezenas de decisões que orientam cada "fase" da jurisprudência do STJ quanto à denúncia genérica. Como paradigma, para a segunda fase (“denúncia 'mais ou menos' genérica”), pode-se citar o acórdão do Habeas Corpus $\mathrm{n}^{\circ}$ 39.598/SP, de relatoria do Ministro Gilson Dipp ${ }^{13}$; para a terceira (decisões que "embora refutem a denúncia omissa, entendem ser dispensável a descrição pormenorizada de condutas"), vale a menção ao acórdão do $\mathrm{HC}^{\circ}$ 58.157/ES, de relatoria do Ministro Haroldo Rodrigues $^{14}$.

No Supremo Tribunal Federal, embora o estágio atual seja semelhante, o caminho foi diferente. Knopfholz explica:

A análise histórica da orientação do Supremo Tribunal Federal destoa daquela do Superior Tribunal de Justiça. Tal qual neste, nos primeiros anos após o advento da Constituição da República o entendimento quase unânime era de ser possível a denúncia genérica. Após 2005, houve uma sensível alteração de posicionamento da 
Suprema Corte (não apenas pela alternância de Ministros, mas, igualmente, pela modificação de entendimento de alguns dos julgadores, tais como o Ministro Gilmar Mendes), repelindo-se as acusações genéricas. Atualmente, em alguns julgados, regride-se para a orientação da possibilidade de denúncia genérica e, em outros, segue-se o atual posicionamento do STJ, segundo o qual são inviáveis as denúncias desprovidas de individualização de condutas, admitindo-se, contudo, que tal individualização prescinde de exaustividade. ${ }^{15}$

Em suma, a primeira parte do problema, ainda que não de forma unânime, tem sido enfrentada pelos Tribunais Superiores. Evidentemente, porém, a solução apresentada não parece estar de acordo com as diretrizes do Código de Processo Penal para o processamento de acusações criminais. Ao admitir a denúncia que não descreve pormenorizadamente as condutas, ainda que se trate de avanço em relação à admissão, pura e simples, de denúncia genérica, os Tribunais Superiores estão dando guarida ao conhecimento de acusações que correm o risco de envolver indivíduos que não praticaram quaisquer condutas criminosas. Embora se possa sustentar que a descrição não exaustiva é melhor que nenhuma descrição, trata-se de situação distante do ideal.

A segunda parte do problema da individualização de condutas, porém, não permite solução intermediária como a que têm adotado os Tribunais Superiores. Afinal, ou se tem a demonstração inequívoca de autoria delitiva, ou o denunciado deve ser absolvido. É neste ponto que ganha relevância a colaboração premiada. Para ilustrar, veja-se a lição de Frederico Valdez Pereira:

\footnotetext{
Essa posição privilegiada, numa comparação com pessoa neutra e apartada do cometimento dos delitos, permite inevitavelmente ao colaborador processual o conhecimento interno de alguma situação objetiva, ainda que restrita, embasada em dados e elementos concretos presenciados pelo agente, os quais devem ser explicitados e detalhados já nos contatos iniciais, para permitir a avaliação desses requisitos internos de procedibilidade da colaboração. Ainda que o informante tenha tido atuação esporádica ou mínima na atividade delituosa, poderá esclarecer a natureza de sua participação e todos os detalhes concretos que lhe permitiram o conhecimento sobre os fatos declarados ao órgãos de persecução penal. ${ }^{16}$
}

Ora, se o colaborador premiado pode contribuir com a investigação porque se encontra em posição privilegiada e tem conhecimento interno das peculiaridades objetivas dos fatos em investigação, podendo detalhá-los às autoridades investigantes, é possível que, da mesma forma, contribua justamente para solucionar, nos crimes empresariais, a dificuldade relativa à responsabilização penal subjetiva. Em tese, no caso dos crimes empresariais, portanto, a colaboração premiada poderia funcionar, não apenas para a mais efetiva punição de crimes, 
mas também como instrumento de controle do poder punitivo do Estado, afastando-se as denúncias e condenações genéricas.

Não há dúvidas de que essa compatibilização é complexa e demanda, sobretudo, a análise empírica da colaboração premiada. É isso que se pretende fazer neste ensaio: além de um breve estudo sobre o instituto da colaboração premiada, analisar-se-á um caso concreto em que o instituto foi utilizado em acusação de crimes empresariais para se verificar se, naquele caso, houve a sua utilização para o fim proposto neste estudo.

\section{A COLABORAÇÃO PREMIADA COMO INSTRUMENTO DE SOLUÇÃO}

Antes da verificação empírica da potencial utilização da colaboração premiada como instrumento de solução para o problema da individualização de condutas nos crimes empresariais, é imperiosa uma análise mais detida do instituto - sem, evidentemente, o objetivo de exaurir o tema e suas nuances -, desde a sua origem até o seu estado atual no ordenamento brasileiro.

\subsection{O DIREITO PENAL PREMIAL}

A colaboração premiada não foi instituída pela atual lei que a disciplina (Lei $\mathrm{n}^{\circ}$ 12.850/2013). Ela faz parte do que a doutrina denomina de direito penal premial. Como explica Pereira, trata-se de "expressão que sugere uma contradição pelo fato de ligar a ideia de benefício ao ramo do direito que se distingue exatamente pela previsão de ameaça de penas e de proteção coativa mediante aplicação de sanções" ${ }^{17}$. Trocando em miúdos, o autor esclarece que o prêmio inserido no âmbito penal deve ser entendido como "um mal menor imposto ao indivíduo que, depois do cometimento de uma conduta punível pelo direito penal, realiza contraconduta colaborativa destinada a diminuir ou elidir a pena prevista para o ilícito originariamente cometido." 18

A contradição acima alertada tem razão de ser. Tradicionalmente, pensa-se o direito penal como instrumento de retribuição e prevenção. Como essas funções, nos crimes de ação penal pública, são revestidas de caráter obrigatório - por força do princípio da 
indisponibilidade e obrigatoriedade -, fica evidente o descompasso entre a ordem legal pátria e um instituto que tem por sua natureza a barganha.

O fato é que, como delineia Norberto Bobbio, houve uma mudança de paradigma com a alteração do modelo constitucional liberal clássico para o pós-liberal: "Nas constituições liberais clássicas, a principal função do Estado parece ser a de tutelar (ou garantir). Nas constituições pós-liberais, ao lado da função de tutela, aparece, cada vez com maior frequência, a função de promover" ${ }^{\prime 19}$. O autor defende, com isso, o aumento das sanções positivas em detrimento das negativas. Nesse sentido, Bobbio esclarece que houve uma mudança no papel do direito na sociedade, "comumente considerado do ponto de vista da sua função predominante, que sempre foi aquela, mais passiva que ativa, de proteger determinados interesses mediante a repressão dos atos desviantes" ${ }^{20}$. Nas constituições pósliberais, como a brasileira, o direito não pode mais "se limitar a tutelar atos conformes às próprias normas, mas tende a estimular atos inovadores - e, portanto, a sua função não é mais apenas protetora, mas também promocional"21.

Com isso, surgem ao lado das sanções negativas ("restituir o mal ao mal" 22, compatível com a noção clássica de pena) as sanções positivas, consistentes em "técnica de estímulo e propulsão a atos considerados socialmente úteis, em lugar da repressão de atos considerados socialmente nocivos" 23 . O prêmio, portanto, "é uma reação a uma ação boa" ${ }^{24}$, ainda que de alguém que tenha agido mal anteriormente.

Logicamente, os benefícios que se concedem na colaboração processual, ao menos sob a perspectiva brasileira, seguem o raciocínio de Bobbio: embora tenha praticado um delito, o colaborador pratica uma ação positiva com o intuito de auxiliar as autoridades a ampliarem uma investigação para, por exemplo, desvendar toda a estrutura do crime. Pega-se a palavra de um personagem para se minuciar o enredo completo (o que é especialmente relevante quando o colaborador é figura coadjuvante em uma organização criminosa, cuja compreensão e punição é extremamente mais relevante ao interesse público).

Fausto Martin de Sanctis dá a sua perspectiva de magistrado sobre essa característica da colaboração premiada, tecendo comentários sobre a natureza ética e estratégica do instituto:

O prêmio punitivo que se concede ao suspeito/acusado visa a uma eficaz busca da verdade. A delação premiada, existente no Brasil desde as Ordenações Filipinas, é ética, útil e estratégica. Ética porque atende às finalidades político-criminais e à 
proteção do bem jurídico. (...) Útil pelo fato de permitir a descoberta precoce de crimes e seus autores ou partícipes, facilitando o trabalho de todos. Por fim, estratégica para as partes, inclusive à defesa, já que o cliente se vê beneficiado com uma pena relativizada sem o custo do processo. ${ }^{25}$

Ao fornecer informações relevantes que permitam a persecução de outros coautores do crime - e, nos mais recentes e notórios casos, restituir ao Estado e às vítimas dos crimes, o produto do crime (na forma de valores para reparação de danos e multas pesadíssimas), o réu colaborador recebe uma contrapartida do Estado, que pode ser a simples redução de pena e a alteração do regime prisional ou o perdão judicial.

\subsection{A LEGISLAÇÃO BRASILEIRA ANTECEDENTE}

A colaboração, enquanto instrumento prático não previsto em lei, esteve presente na história brasileira em momentos notórios: desde as Ordenações Filipinas, como mencionado por Sanctis acima, passando pela formulada por Joaquim Silvério dos Reis em detrimento de Joaquim José da Silva Xavier, que acabou enforcado e esquartejado em 21 de abril de 1792, até os expedientes usuais de obtenção de provas do Regime Militar de 1964-1985, a delação de comparsas sempre foi comum.

Após a redemocratização, alguns bons anos foram necessários ao desenvolvimento do que hoje é a colaboração premiada da Lei $n^{\circ}$ 12.850/2013 (influenciada, sobretudo, por convenções internacionais contra a corrupção ${ }^{26}$ ).

De qualquer forma, é certo que o conceito de direito penal premial há muito está inserido no ordenamento brasileiro. Como exemplo, podem-se citar os artigos 15, 16, 65, III, d, e $159, \S 4^{\circ}$, do Código Penal, que preveem benefícios penais para os agentes que, de forma voluntária, contribuem com a Justiça, seja durante a execução do crime (nos casos da desistência voluntária, do arrependimento eficaz ou na causa de diminuição de pena no crime de extorsão mediante sequestro no caso do coautor que denuncia os concorrentes para facilitar a liberação do refém), seja após (no caso do arrependimento posterior e da confissão espontânea). Em todas as situações do Código Penal, há a previsão de um benefício para o agente que facilita a apuração de crimes, em um aceno ao que hoje se pode formalizar por meio de um acordo.

Sob a denominação colaboração, a legislação penal especial já previa, antes de 2013, a possibilidade de concessão de benefícios aos acusados colaboradores (em sentido amplo): por 
exemplo, as Leis $n^{\circ}$ 7.492/86, 8.137/90, 8.072/90, 9.613/98 e 11.343/03 contêm dispositivos que premiam a confissão espontânea como causa especial de redução de pena - de forma mais impactante que a confissão como circunstância atenuante do Código Penal.

A Lei $\mathrm{n}^{\circ}$ 9.807, de 13 de julho de 1999, por sua vez, foi o primeiro diploma nacional voltado à disciplina da colaboração como instrumento formal de obtenção de prova com a previsão de perdão judicial para o acusado que prestasse informações efetivas e voluntárias para a investigação e o processo criminal.

Com base na previsão legal, alguns Magistrados passaram a homologar acordos de colaboração celebrados entre o Ministério Público e os acusados, em moldes semelhantes ao que se verifica atualmente. As formalidades ainda eram cinzentas, todavia.

O Juízo da $13^{\text {a }}$ Vara Federal de Curitiba foi um dos pioneiros na utilização da colaboração processual em grandes operações da Polícia Federal e do MPF, como no rumoroso Caso Banestado. Em livro publicado, o magistrado Sérgio Fernando Moro consignou a discricionariedade verificada na aplicação da Lei no 9.807/99 e a falta de critérios legais para a sua aplicação - defendendo, porém, a resolução prática dos conflitos e questionamentos procedimentais quanto à celebração do acordo:

\begin{abstract}
A concessão de tais benefícios é indissociável da realização de certo juízo discricionário quanto à oportunidade e à conveniência da colaboração. Ilustrativamente, não se vislumbra interesse da Justiça na realização de acordo de colaboração com o chefe do grupo criminoso, mesmo que este se disponha a identificar todos os seus comandados, o que preencheria, em tese, a hipótese do art. 13, I, da Lei n. 9.807/99. Da mesma forma, não se vislumbra motivo para a concessão do benefício a um criminoso, mesmo quando este tenha revelado a localização do produto do crime, o que preencheria a hipótese do art. 13, I, da Lei n. 9.807/99, se essa descoberta se mostrasse inevitável no curso da investigação, ou seja, se ocorresse mesmo sem a colaboração, ainda que levasse um pouco mais de tempo. ${ }^{27}$
\end{abstract}

Evidentemente, o posicionamento do autor encontrava extrema resistência na doutrina e na advocacia, sobretudo diante de situações práticas que claramente afetavam o exercício de defesa. Exemplos eram os reinterrogatórios realizados após a secreta (para a defesa) celebração do acordo, nos quais o corréu colaborador, ainda falando formalmente como um acusado comum, confessava os crimes e delatava os codenunciados. Sua palavra era tomada como elemento de prova e os delatados eram condenados. Moro refutava as críticas, sob o argumento de que "somente quem tem conhecimento sobre a atividade criminal, com 
condições de providenciar informações ou provas relevantes são, em geral, os próprios criminosos". ${ }^{28}$

Embora a Lei $n^{\circ}$ 9.807/99 tenha permitido a obtenção de efetivos resultados com os acordos nela previsto, era evidente a necessidade de uma melhor disciplina do instituto. Foi o que fez a Lei $\mathrm{n}^{\mathrm{o}} 12.850$, de 2 de agosto de 2013.

\title{
2.3. A LEI $12.850 / 2013$ E A NATUREZA JURÍDICA DA COLABORAÇÃO
} PROCESSUAL

Longe de se tratar de um diploma completo e irrefutável sobre o tema, a lei que também define as organizações criminosas trouxe uma série de - aparentes - novos requisitos e regramentos para a colaboração premiada.

Dois aspectos etimológicos da lei são importantes para a compreensão imediata do instituto. Em primeiro lugar, formalizou-se a nomenclatura "colaboração premiada", em substituição à mais simplória "delação premiada". Não que a segunda esteja errada; a “delação" é uma espécie do gênero "colaboração". A colaboração premiada poderá ocorrer na forma de delação (com o colaborador indicando outros autores do fato), mas não se trata de um requisito (em tese, o réu poderá se beneficiar caso simplesmente confesse o crime e, por exemplo, forneça elementos que possibilitem a recuperação dos valores desviados).

O outro aspecto importante é que a lei expressamente definiu a colaboração premiada como um "meio de obtenção de prova", e não um "meio de prova". Há uma diferença relevante entre os termos, como explica Gustavo Badaró:

\begin{abstract}
Enquanto os meios de prova são aptos a servir, diretamente, ao convencimento do juiz sobre uma veracidade ou não de uma afirmação (p. ex., o depoimento de uma testemunha, ou o teor de uma escritura pública), os meios de obtenção de provas (p.ex. uma busca e apreensão) são instrumentos para a colheita de elementos ou fontes de provas, estes sim, aptos a convencer o julgador (p.ex.: um extrato bancário [documento] encontrado em uma busca e apreensão domiciliar). Ou seja, enquanto o meio de prova se presta ao convencimento direto do julgador, os meios de obtenção de provas somente indiretamente, e dependendo do resultado de sua realização, poderão servir à reconstrução da história dos fatos. ${ }^{29}$
\end{abstract}

No mesmo sentido, Pierpaolo Cruz Bottini afirma que diferencia o meio da prova, no sentido de que "a prova é capaz de sustentar uma acusação ou uma condenação. O meio é apenas um instrumento para que as autoridades possam alcançar provas efetivas". 30 
Ressaltando a posição dos autores, o Supremo Tribunal Federal já pôde se pronunciar sobre a natureza jurídica da colaboração premiada: no julgamento do Habeas Corpus $\mathrm{n}^{\circ}$ 127483/PR, o Ministro Dias Toffoli, em posicionamento unânime do Plenário, publicado em 4 de fevereiro de 2015, reconheceu que "a homologação não representa juízo de valor sobre as declarações eventualmente já prestadas pelo colaborador à autoridade judicial ou ao Ministério Público"31. Ou seja, a simples celebração do acordo entre o Ministério Público e o acusado e a sua posterior homologação pelo Poder Judiciário não formalizam a prova; apenas se institui o meio para a obtenção da eventual prova, que se consolidará com o depoimento judicial e o seu acompanhamento com elementos de corroboração produzidos perante o contraditório.

A Lei $n^{\circ} 12.850 / 2013$ é igualmente clara quanto aos resultados que se objetivam quando da celebração do acordo de colaboração premiada. Segundo o caput do art. $4^{\circ}$, o réu poderá pleitear benefícios (genericamente o perdão judicial, a redução da pena privativa de liberdade em até dois terços ou a sua substituição por pena restritiva de direitos) caso sua colaboração obtenha um ou mais dos resultados previstos no mesmo dispositivo.

O procedimento para a celebração do acordo de colaboração premiada está disposto nos parágrafos do art. $4^{\circ}$ da Lei $n^{\circ} 12.850 / 13$. Em resumo, a negociação, segundo a lei, será realizada entre a autoridade policial, o Ministério Público e o investigado ou acusado, acompanhado de seu defensor. O Juiz, portanto, não pode participar da negociação, somente recebendo o termo de acordo já finalizado para a homologação. A doutrina questiona a participação da polícia na celebração do acordo. Segundo Renato Brasileiro de Lima o art. 129, I, da Constituição Federal, confere legitimidade exclusiva ao Ministério Público para o exercício da ação penal pública, de modo que a autoridade policial somente poderia "sugerir ao investigado a possibilidade de celebração do acordo",32.

Homologado o acordo, buscar-se-ão os resultados previstos no art. $4^{\circ}$, caput, da Lei ${ }^{\circ}$ 12.850/13. Alcançando-se um ou mais resultados, conceder-se-ão os seguintes benefícios: a) não oferecimento de denúncia; b) redução da pena em até dois terços, se o acordo for celebrado antes da sentença, ou até metade, se após; c) substituição da pena privativa de liberdade por restritiva de direitos; d) progressão do regime sem os requisitos temporais da legislação comum; e) perdão judicial, para o caso de acusado com ação penal já instaurada que preencha certos requisitos e pressupostos. 
Os dois primeiros resultados (qual seja aquele disciplinado pelo art. $4^{\circ}$, I e II, da Lei $\mathrm{n}^{\circ}$ 12.850/2013), porém, é o que interessa para os fins deste estudo. Como o sucesso da colaboração (em termos de obtenção de benefício pelo réu colaborador) pode depender da "identificação dos demais coautores e partícipes da organização criminosa e das infrações penais por eles praticadas" e da "revelação da estrutura hierárquica e da divisão de tarefas da organização criminosa", passa-se a verificar se, na prática, o instrumento processual tem funcionado de modo a individualizar condutas de acusados por crimes empresariais.

\section{ESTUDO DE CASO: A CONDENAÇÃO DO PRIMEIRO CASO "OAS" (OPERAÇÃO LAVA-JATO)}

Já se identificou, neste estudo, o problema da individualização de condutas dos crimes empresariais e se sugeriu, como hipótese teórica, a colaboração premiada como potencial instrumento para a sua solução, na medida em que se trata de meio de obtenção de prova que privilegia o réu colaborador que, mediante acordo e em razão de sua posição na estrutura ilícita, pode vir a fornecer elementos de identificação de coautores e detalhes da hierarquia da organização criminosa.

Passa-se, então, à análise de um caso concreto para se verificar se, na prática, o raciocínio teórico apresentado foi - ou tem sido - empregado na solução de casos reais.

Como se trata de um ensaio, com limitações inerentes a um artigo acadêmico, não se pretende demonstrar que toda e/ou qualquer sentença de processo instruído por meio de colaborações premiadas seja melhor fundamentada quanto aos elementos de individualização autoria delitiva. Também não se pretende pinçar uma sentença específica na qual a colaboração tenha sido sabidamente utilizada para individualizar responsabilidades criminais. Embora um exemplo concreto pudesse acenar para a funcionalidade do instituto, a escolha arbitrária de um caso específico favorável à tese que ora se propõe poderia soar como desonestidade intelectual.

Em razão disso, escolheu-se, no âmbito da Operação Lava-Jato, justamente a primeira sentença proferida nos muitos casos em trâmite na $13^{\mathrm{a}}$ Vara Federal de Curitiba/PR em que os representantes legais de uma empresa (empreiteira OAS) viram-se denunciados por crimes praticados na atividade empresarial. 
Trata-se da sentença da Ação Penal no 5083376-05.2014.404.7000 ${ }^{33}$, que teve 9 (nove) denunciados ${ }^{34}$ pelas práticas dos crimes de corrupção (arts. 317 e 333 do Código Penal), lavagem de dinheiro (art. $1^{\circ}$, caput, inciso V, da Lei ${ }^{\circ}$ 9.613/1998), organização criminosa (art. $2^{\text {o }}$ da Lei ${ }^{\circ}$ 12.850/2013) e uso de documento falso (arts. 299 e 304 do Código Penal).

Em resumo, o grupo OAS teria participado de duas frentes de atividades ilícitas: a) em primeiro lugar, teria participado de cartel com outras empreiteiras para vencer licitações previamente escolhidas pelo "clube" (no caso, as licitações vencidas pela empresa foram as relativas às obras das refinarias da Petrobras identificadas sob os acrônimos REPAR e da RNEST); b) em segundo lugar, e "em decorrência do esquema criminoso", o grupo OAS, por seus dirigentes, teria pago propina à Diretoria de Abastecimento da Petrobras, destinando 1\% (um por cento) dos valores das licitações ao Diretor da referida área e corréu colaborador Paulo Roberto Costa. Os valores teriam sido "lavados", antes de encaminhados aos destinatários da propina (o Diretor de Abastecimentos e partidos políticos envolvidos) mediante contratos de prestação de serviços simulados com empresas controladas pelo corréu colaborador Alberto Youssef e pelo corréu Waldomiro Oliveira.

Todos os dirigentes da empresa foram condenados, em maior ou menor proporção: a) Léo Pinheiro e Agenor Medeiros foram condenados por corrupção ativa - duas vezes, lavagem de dinheiro - doze vezes, e crime de organização criminosa, às penas de 16 anos e 4 meses de reclusão; b) Mateus Oliveira e João Ricardo Breghirolli foram condenados por lavagem de dinheiro - doze vezes - e organização criminosa, à pena de 11 anos de reclusão; c) Fernando Augusto Stremel de Andrade foi condenado por uma lavagem de dinheiro à pena de 4 anos de reclusão.

O número de pessoas ligadas à empresa, por si só, parece indicar a existência de indícios robustos de autoria. Afinal, caso contrário e seguindo-se a lógica das denúncias genéricas tratadas neste estudo, apenas o presidente e diretores de alto escalão seriam formalmente acusados. Como, no caso, além desses dois últimos, outros funcionários de mais baixo escalão foram denunciados, há a presunção de que elementos de prova consideráveis levaram o Ministério Público Federal a denunciar uma série de executivos do grupo OAS.

Essa constatação não prejudica o objeto deste ensaio. Considerando-se que, além dos múltiplos executivos (que não foram denunciados por sua posição hierárquica, mas por indícios concretos que presuntivamente os individualizaram na prática delituosa), acabou 
denunciado o presidente da empresa, a análise da individualização da conduta por meio de provas obtidas pelas declarações de réus colaboradores persiste. Afinal, o envolvimento pessoal do líder de uma corporação precisa ser inequivocamente demonstrado, não bastando apenas sua posição hierárquica para a responsabilização criminal. Como Léo Pinheiro foi condenado a uma alta reprimenda corporal, questiona-se se, na sua condenação, houve a utilização de elementos de prova oriundos de colaboração premiada devidamente corroborados por provas autônomas.

A princípio, a resposta é positiva. Além de uma série de provas documentais, e também oriundas de interceptação telefônica e telemática, a sentença se utilizou da palavra de colaboradores para identificar e individualizar condutas praticadas pelo acusado Léo Pinheiro. Além dos codenunciados Paulo Roberto Costa e Alberto Youssef, a sentença também se utilizou de depoimentos de colaboradores não denunciados, como Augusto Ribeiro de Mendonça Neto e Júlio Camargo. Os delatores descreveram circunstâncias que implicariam o então presidente da OAS.

Augusto Ribeiro de Mendonça Neto foi o primeiro a ser mencionado pelo Juízo da $13^{\mathrm{a}}$ Vara Federal de Curitiba quando da análise da autoria delitiva dos executivos da OAS. Consignou-se, às fls. 31 e 70 da sentença o seguinte:

273. Também confirmou a participação da OAS no cartel e nos ajustes das licitações, a partir aproximadamente de 2006 e afirmou que ela teria sido representada inicialmente pelo acusado José Adelmário Pinheiro Filho e depois por Agenor Franklin Magalhães Medeiros.

(...)

443. Augusto Ribeiro de Mendonça Neto, dirigente da Setal Óleo e Gás S/A, uma das empreiteiras participantes do cartel, declarou, como visto nos itens 273-274, que José Adelmário representava a OAS nas reuniões do cartel, sendo sucedido por Agenor Medeiros.

444. Também declarou que a atividade do cartel estava vinculada ao pagamento de propinas aos dirigentes da Petrobras (...)

Os corréus colaboradores Paulo Roberto Costa e Alberto Youssef também ratificaram o envolvimento direto do referido acusado, relacionando-o diretamente ao pagamento de propinas e ao ajustes realizado nas licitações que configurou o crime de cartel.

A sentença analisou, em relação a outros acusados vinculados à OAS, uma série de documentos que os ligariam aos crimes apurados. São provas oriundas de buscas e apreensões, interceptações de mensagens enviadas por aparelhos celulares e registros de 
entrada e saída do escritório de Alberto Youssef. Em relação a Léo Pinheiro (e também a Agenor Medeiros), porém, as palavras dos colaboradores foram os elementos mais relevantes para a individualizada responsabilização criminal.

O Juízo da $13^{\mathrm{a}}$ Vara Federal de Curitiba, sabedor da indispensabilidade de provas autônomas e independentes das simples palavras dos colaboradores, indicou outro elemento de prova para a confirmação da autoria: o fato de que, na qualidade de presidente da OAS, não teria ele determinado "qualquer apuração interna efetiva sobre os fatos", faltando-lhe a "postura que se esperava da OAS, em especial do presidente José Adelmário".

Se os elementos complementares indicados pela sentença como prova autônoma ou circunstancial da autoria delitiva são suficientes, não é objetivo deste artigo afirmar. O que se pode concluir é que a responsabilização penal do presidente da OAS dependeu, de forma muito relevante, das palavras de colaboradores premiados nos termos da Lei $n^{\circ}$ 12.850/2013. Ainda que se possa questionar a suficiência dos elementos de prova autônomos obtidos a partir dos depoimentos dos colaboradores, é certo que a sentença foi confirmada, quanto ao reconhecimento da autoria de Léo Pinheiro, pelo Tribunal Regional Federal da $4^{\mathrm{a}}$ Região no julgamento da Apelação Criminal no 5083376-05.2014.4.04.7000/PR ${ }^{35}$.

É evidente que qualquer conclusão definitiva quanto ao tema é precipitada. No entanto, parece que o referido acusado condenado teve, na análise da autoria delitiva que lhe foi imputada, uma descrição específica sobre os atos praticados (em contrariedade à regra dos crimes de natureza empresarial), sendo a prova decorrente da colaboração premiada utilizada como instrumento de individualização de conduta. Mais análises práticas, porém, são necessárias para maiores considerações sobre o atendimento ao requisitos do instituto e à sua natureza jurídica, sobretudo no que diz respeito à extensão dos meios de prova autônomos e independentes das palavras dos colaboradores que devam ser utilizados para a formação do juízo condenatório.

\section{CONCLUSÃO}

Neste ensaio, buscou-se verificar em que medida a utilização das provas oriundas das colaborações premiadas pode se apresentar como possível solução (ou instrumento) a um problema recorrente dos crimes de natureza empresarial, qual seja a dificuldade de 
individualização de condutas praticadas genericamente na empresa (isto é, sem a delimitação exata das funções executadas por administradores específicos).

Para tanto, em primeiro lugar, partiu-se de um enfrentamento do problema e o posicionamento dos Tribunais Superiores quanto ao tema. Na sequência, este estudo traçou um breve panorama do instituto da colaboração premiada, em análise que possibilitou, em tese, a conclusão de que a colaboração premiada pode ter, hipoteticamente, uma função diferenciada como instrumento de individualização de condutas em ações penais que envolvam crimes praticados na atividade empresarial.

A partir da apresentação do problema e da sugestão teórica para a sua solução, adentrou-se em caso específico, oriundo da Operação Lava-Jato, para verificar se, na prática, a colaboração pode ser, de fato, utilizada como solução ao problema da individualização de condutas. Por meio da análise da condenação do presidente de empreiteira profundamente envolvida nos esquemas de cartel e corrupção (entre outros crimes), buscou-se verificar se sua condenação - com a devida individualização de autoria - utilizou-se de provas oriundas de depoimentos de réus colaboradores de modo a evitar uma condenação presuntiva.

Verificou-se que, no caso concreto, grande parte do acervo probatório utilizado para condenar o Presidente da empresa foi oriundo de palavras de colaboradores. Com isso, ainda que de forma incipiente, a hipótese deste artigo foi confirmada em exemplo prático, indicando, sem prejuízo de maiores estudos e outras análises praticadas, que a colaboração premiada pode contribuir para a individualização de condutas em crimes empresariais.

Não se nega que consideração apresentada no capítulo introdutório, de que a colaboração premiada pode funcionar como instrumento de garantia no processo penal, pode ser refutada. Afinal, por um simples silogismo, poder-se-ia afirmar que a palavra de um corréu colaborador jamais poderia resolver o problema da ausência de individualização de condutas porque, ainda que se admita a denúncia genérica (ou com descrição não exaustiva), uma condenação jamais poderia se sustentar sem a indicação das provas de autoria delitiva. Com isso, em uma instrução penal em que não se produzam elementos de prova que impliquem o dirigente de uma empresa, não haveria que se falar em necessidade de instrumentos exógenos para o exercício da garantia do in dubio pro reo, por exemplo.

Sem dúvidas, esse raciocínio faz sentido. Em um cenário com o binômio ausência de provas e absolvição, a utilização da colaboração premiada não teria qualquer função garantidora de direitos. Afinal, se haveria a absolvição automática em razão da ausência de 
elementos de autoria, seria dispensável qualquer outro instrumento (sobretudo um instrumento que implique uma condenação criminal).

No entanto, pode-se analisar o problema sob outra perspectiva: caso se esteja diante de uma condenação por presunção (isto é, condenando-se o dirigente da empresa simplesmente por sua condição societária ou administrativa), a utilização da colaboração premiada pode, por um lado, afastar responsabilidades e, por outro, conferir maior precisão técnica a uma condenação devida. Nesses casos, a conclusão deste artigo tem relevância, sem prejuízo, novamente, de maiores estudos e aprofundamento quanto à extensão do valor probatório da colaboração premiada e da necessidade de provas autônomas para um juízo condenatório.

\section{REFERÊNCIAS BIBLIOGRÁFICAS}

BADARÓ, Gustavo. Processo Penal. Rio de Janeiro: Elsevier, 2012.

BOBBIO, Norberto. Da estrutura à função: novos estudos de teoria do direito. Tradução de Daniela Beccaccia Versiani. Barueri: Manole, 2007.

BOTTINI, Pierpaolo Cruz. Os limites da delação premiada. Disponível em: http://www1.folha.uol.com.br/opiniao/2016/10/1822634-os-limites-da-delacaopremiada.shtml Acesso em: 15 de outubro de 2016.

BRASIL, Superior Tribunal de Justiça. HC 39.598/SP, da 6 Turma. Relator: Min. Gilson Dipp. Julgado em 7.4.2005. DJ 2.5.2005.

BRASIL, Superior Tribunal de Justiça. HC 58.157/ES/SP, da 6 Turma. Relator: Min. Haroldo Rodrigues. Julgado em 18.8.2009. DJ 8.9.2009.

BRASIL, Supremo Tribunal Federal. Plenário. HC 127483/PR. Rel: Min. Dias Toffoli. DJ 4.2.2016.

DOTTI, René Ariel. Algumas reflexões sobre o "Direito Penal dos negócios". In: DOTTI, René Ariel; PRADO, Luiz Régis (org.). Doutrinas Essenciais - Direito Penal Econômico e da Empresa. Teoria Geral da Tutela Penal Transindividual. Volume 1. São Paulo: RT, 2011.

DOTTI, René Ariel. Curso de Direito Penal: parte geral. 4ª Edição. São Paulo: RT, 2012.

HUNGRIA, Nelson. Comentários ao Código Penal. Volume VI. $3^{\text {a }}$ Edição. Rio de Janeiro: Forense, 1955.

KNOPFHOLZ, Alexandre. A denúncia genérica nos crimes econômicos. Porto Alegre: Nuria Fabris, 2013. 
LIMA, Renato Brasileiro. Legislação criminal especial comentada. Salvador: Juspodivm, 2015 .

MORO, Sérgio Fernando. Crime de lavagem de dinheiro. São Paulo: Saraiva, 2010.

MUSACCHIO, Vincenzo. Derecho penal económico, criminalidade organizada y Union Europea. Revista Brasileira de Ciências Criminais. Ano 14. $\mathrm{N}^{\circ}$ 60. São Paulo: Mai/Jun. 2006.

PEREIRA, Frederico Valdez. Delação premiada - Legitimidade e Procedimento - Aspectos Controvertidos do Instituto da Colaboração Premiada de Coautor de Delitos como Instrumento de Enfrentamento do Crime Organizado. $3^{\text {a }}$ Edição. Curitiba: Juruá, 2016.

PEREIRA, Frederico Valdez. Valor probatório da colaboração processual (Delação Premiada). Revista dos Tribunais. Ano 98. Vol. 879. Janeiro/2009.

SANCTIS, Fausto Martin de. Crime organizado e lavagem de dinheiro: destinação de bens apreendidos, delação premiada e responsabilidade social. 2ª Edição. São Paulo: Saraiva, 2015.

${ }^{1}$ DOTTI, René Ariel. Algumas reflexões sobre o "Direito Penal dos negócios". In: DOTTI, René Ariel; PRADO, Luiz Régis (org.). Doutrinas Essenciais - Direito Penal Econômico e da Empresa. Teoria Geral da Tutela Penal Transindividual. Volume 1. São Paulo: RT, 2011. P. 718.

${ }^{2}$ DOTTI, René Ariel. Curso de Direito Penal: parte geral. $4^{a}$ Edição. São Paulo: RT, 2012. P. 252.

${ }^{3}$ HUNGRIA, Nelson. Comentários ao Código Penal. Volume VI. $3^{\text {a }}$ Edição. Rio de Janeiro: Forense, 1955. P. 269.

${ }^{4}$ KNOPFHOLZ, Alexandre. A denúncia genérica nos crimes econômicos. Porto Alegre: Nuria Fabris, 2013. P. 77.

${ }^{5}$ Ibidem.

${ }^{6}$ Ibidem.

${ }^{7}$ Ibidem, p. 78.

${ }^{8}$ Ibidem, p. 135-136.

${ }^{9}$ MUSACCHIO, Vincenzo. Derecho penal económico, criminalidade organizada y Union Europea. Revista Brasileira de Ciências Criminais. Ano 14. Nº 60. São Paulo: Mai/Jun. 2006. P. 221.

${ }^{10}$ KNOPFHOLZ, op. cit., p. 206.

${ }^{11}$ BRASIL, Superior Tribunal de Justiça. RHC 906/MG, da 6a Turma. Relator: Min. José Cândido. Julgado em 18.12.1990. DJ 18.2.1991.

${ }^{12}$ KNOPFHOLZ, op. cit., p. 206.

${ }^{13}$ BRASIL, Superior Tribunal de Justiça. HC 39.598/SP, da 6 Turma. Relator: Min. Gilson Dipp. Julgado em 7.4.2005. DJ 2.5.2005.

${ }^{14}$ BRASIL, Superior Tribunal de Justiça. HC 58.157/ES/SP, da 6 Turma. Relator: Min. Haroldo Rodrigues. Julgado em 18.8.2009. DJ 8.9.2009.

${ }^{15}$ KNOPFHOLZ, op.cit., p. 220.

16 PEREIRA, Frederico Valdez. Valor probatório da colaboração processual (Delação Premiada). Revista dos Tribunais. Ano 98. Vol. 879. Janeiro/2009. 
${ }^{17}$ PEREIRA, Frederico Valdez. Delação premiada - Legitimidade e Procedimento - Aspectos Controvertidos do Instituto da Colaboração Premiada de Coautor de Delitos como

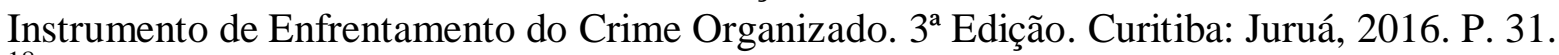

${ }^{18}$ Ibidem, p. 31.

${ }^{19}$ BOBBIO, Norberto. Da estrutura à função: novos estudos de teoria do direito. Tradução de Daniela Beccaccia Versiani. Barueri: Manole, 2007. P. 13.

${ }^{20}$ Ibidem, p. 23 e 24.

${ }^{21}$ Ibidem.

${ }^{22}$ Ibidem.

${ }^{23}$ Ibidem.

${ }^{24}$ Ibidem.

${ }^{25}$ SANCTIS, Fausto Martin de. Crime organizado e lavagem de dinheiro: destinação de bens apreendidos, delação premiada e responsabilidade social. 2 ${ }^{a}$ Edição. São Paulo: Saraiva, 2015. P. 182.

${ }^{26}$ Convenções de Palermo e de Mérida da ONU, promulgadas pelos Decretos $n^{\circ}$ 5.015/2004 e $5687 / 2006$.

${ }^{27}$ MORO, Sérgio Fernando. Crime de lavagem de dinheiro. São Paulo: Saraiva, 2010. P. 110111.

${ }^{28}$ Ibidem, p. 110-111.

${ }^{29}$ BADARÓ, Gustavo. Processo Penal. Rio de Janeiro: Elsevier, 2012. P. 270.

30 BOTTINI, Pierpaolo Cruz. Os limites da delação premiada. Disponível em: $<$ http://www1.folha.uol.com.br/opiniao/2016/10/1822634-os-limites-da-delacaopremiada.shtml>. Acesso em: 15 de outubro de 2016.

${ }^{31}$ BRASIL, Supremo Tribunal Federal. Plenário. HC 127483/PR. Rel: Min. Dias Toffoli. DJ 4.2.2016.

${ }^{32}$ LIMA, Renato Brasileiro. Legislação criminal especial comentada. Salvador: Juspodivm, 2015.

${ }^{33}$ CURITIBA. Justiça Federal do Paraná. 13 ${ }^{\mathrm{a}}$ Vara Federal. Ação Penal $\mathrm{n}^{\mathrm{o}}$ 508337605.2014.404.7000. Sentença publicada em 5.8.2015.

${ }^{34}$ Alberto Youssef, Paulo Roberto Costa, Waldomiro Oliveira, José Aldemário Pinheiro Filho, Agenor Franklin Magalhães Medeiros, Mateus Coutinho de Sá Oliveira, José Ricardo Nogueiro Breghirolli, Fernando Augusto Stremel Andrade e João Alberto Lazzari.

35 PORTO ALEGRE. Tribunal Regional Federal da $4^{a}$ Região. Apelação Penal no 508337605.2014.4.04.7000/PR. Relator: Desembargador Federal João Pedro Gebran Neto. Acórdão publicado em 1.2.2017. 